Board of Governors of the Federal Reserve System

International Finance Discussion Papers

Number 683

September 2000

\title{
MARKOV REGIME-SWITCHING AND UNIT ROOT TESTS
}

\author{
Charles R. Nelson, Jeremy Piger and Eric Zivot
}

NOTE: International Finance Discussion Papers are preliminary materials circulated to stimulate discussion and critical comment. References in publications to International Finance Discussion Papers (other than an acknowledgment that the writer has had access to unpublished material) should be cleared with the author or authors. Recent IFDPs are available on the Web at www.bog.frb.fed.us. 


\title{
MARKOV REGIME-SWITCHING AND UNIT ROOT TESTS
}

\author{
Charles R. Nelson, Jeremy Piger and Eric Zivot ${ }^{\star}$
}

\begin{abstract}
We investigate the power and size performance of unit root tests when the true data generating process undergoes Markov regime-switching. All tests, including those robust to a single break in trend growth rate, have very low power against a process with a Markov-switching trend growth rate as in Lam (1990). However, for the case of business cycle non-linearities, unit root tests are very powerful against models used as alternatives to Lam (1990) that specify regime-switching in the transitory component of output. Under the null hypothesis, the received literature documents size distortions in Dickey-Fuller type tests caused by a single break in trend growth rate or variance. We find these results do not generalize to most parameterizations of Markov-switching in trend or variance. However, Markov-switching in variance can lead to over-rejection in tests robust to a single break in the level of trend.
\end{abstract}

Keywords: unit root, stochastic trends, deterministic trends, Markov-switching, structural change, heteroskedasticity

Nelson is professor of economics at the University of Washington, Zivot is an assistant professor of economics at the University of Washington and Piger is an economist in the International Finance Division of the Federal Reserve Board. Nelson and Piger acknowledge support from the Van Voorhis endowment at the University of Washington. Nelson and Zivot acknowledge support from the National Science Foundation under grant SBR-9711301 and Nelson from grant SES9818789. Piger acknowledges support from the Grover and Creta Ensley Fellowship at the University of Washington. The authors are grateful to Chang-Jin Kim, James Morley, Chris Murray, Dick Startz, participants at the 1999 NBER/NSF time series conference, and two anonymous referees for helpful comments. Responsibility for errors are entirely the authors'. This paper is based on chapter 1 of Piger's Ph.D. dissertation at the University of Washington. The views in this paper are solely the responsibility of the authors and should not be interpreted as reflecting the views of the Board of Governors of the Federal Reserve System or of any other person associated with the Federal Reserve System. 


\section{Introduction}

Since the publication of James Hamilton's seminal 1989 Econometrica paper many authors have employed Markov-switching to model regime change in economic time series. A recent search yielded more than 250 citations of Hamilton's paper, many investigating some sort of Markov regime change in an empirical model. Examples include investigations of business cycle asymmetry (Hamilton, 1989; Lam, 1990), heteroskedasticity in time series of asset prices (Schwert , 1989b and 1996; Turner, Startz and Nelson, 1989; Garcia and Perron, 1996), the effects of inflation on UK commercial property values (Barber, Robertson, and Scott, 1997), the effects of oil prices on U.S. GDP growth (Raymond and Rich, 1997), an inflation targeting rule (Dueker and Fischer, 1996), labor market recruitment (Storer, 1996), the nominal exchange rate (Engel, 1994), the dividend process (Driffill and Sola, 1998), government expenditure (Rugemurcia, 1995), and the level of merger and acquisition activity (Town, 1992).

A separate area of interest in the time series literature, represented in work such as Nelson and Plosser (1982) and summarized nicely in Phillips and Xiao (1998), involves testing the null hypothesis that an economic time series has a unit root, or is $\mathrm{I}(1)$, versus the alternative that the series is (trend) stationary, or I(0). Using standard diagnostic tests for a unit root many researchers are unable to reject the unit root null hypothesis for macroeconomic and financial time series such as GDP, interest rates, and exchange rates. Perron (1989) argues that the evidence in favor of units root has been overstated, as standard unit root tests have very low power against a trend stationary alternative with structural breaks in the level or growth rate of trend. Perron remedied this problem by augmenting the Augmented Dickey-Fuller test with dummy variables to account for one structural break in the series. Christiano (1992), Banerjee, Lumsdaine and Stock (1992), and Zivot and Andrews (1992) extend the Perron methodology to 
endogenous estimation of the date the structural break occurs while Lumsdaine and Papell (1997) consider a test robust to two structural breaks. Hereafter we will refer to this class of tests as Perron-type tests. Leybourne, Mills and Newbold (1998) demonstrate a converse problem, that standard unit root tests can generate spurious rejections when there is a single structural break in trend under the null hypothesis. In this case, an I(1) series that undergoes structural change may appear to be $\mathrm{I}(0)$. Hamori and Tokihisa (1997) point out that a single structural break in variance can also cause size distortions for standard unit root tests.

Given the extensive use of unit root tests on economic time series and the seemingly good fit Markov-switching models provide many of these same series, it is natural to ask what effects Markov-switching regime change has on both standard unit root tests and Perron-type tests. Examples of where this issue may be relevant in the literature are not hard to find. Evans and Wachtel (1993) perform standard unit root tests on the price level and based on a failure to reject suggest an I(1) Markov-switching trend model for prices. Garcia and Perron (1996) argue for an $\mathrm{I}(0)$ Markov-switching trend and variance model of the inflation and real interest rates based on unit root tests performed by Perron (1990) suggesting these series were $\mathrm{I}(0)$ if one break in the level of trend is allowed. Finally, many studies that employ a Markov-switching variance or trend growth rate simply assume a unit root in the series of interest without any pre-testing, most likely because unit root tests from previous studies suggest the series are I(1). Examples include Hamilton's original paper for GNP, Cecchetti and Mark (1990) for consumption and dividends, and Engel (1994) for the nominal exchange rate.

In this study we investigate the effects of several types of Markov regime-switching on unit root tests, focusing on regime change in trend growth rate and variance, the form of structural change most often considered in the macroeconomics and finance literature. The literature 
surrounding structural breaks and unit root tests provides some insight into the size and power effects of a pre-specified number of breaks in trend growth rate on standard unit root tests. However, it is not clear that these results generalize to the case of endogenous, Markovswitching breaks in trend. Perhaps the closest to addressing this question is Balke and Fomby (1991) who demonstrate that standard unit root tests continue to have very low power when a series has endogenous, probabilistic breaks in trend growth rate. However, the process driving their breaks is an independent Bernoulli process, not a Markov-switching process and they do not consider the performance of Perron-type tests. With regards to regime change in variance, several authors have considered the effects of GARCH type heteroskedasticity on unit root tests, for example Pantula (1988), Kim and Schmidt (1993), Seo (1999) and Hecq (1995), the latter considering the effects on Perron-type tests. However, the effects of Markov-switching in variance has not been considered. The only studies the authors are aware of investigating the effects of Markov regime-change in a testing framework are Evans and Lewis (1993) and Hall, Psaradakis and Sola (1997) who conclude that Markov-switching in trend growth rate or in the cointegrating vector will weaken the evidence in favor of cointegration in a bivariate system.

The paper is organized as follows: In Section 2 we evaluate the performance of unit root tests when the true data generating process undergoes regime switching but is otherwise $\mathrm{I}(0)$. In line with previous literature, we find that standard unit root tests do a poor job of distinguishing this model from an integrated process. However, we also find that Perron-type tests have very low power in this case. The Markov-switching trend model has often been used to model business cycle asymmetry. Thus, we also consider alternative Markov-switching models of business cycle asymmetry, in particular a model by Kim and Nelson (1999) which allows regime switching in the transitory component. Unit root tests have very good power against this generating process, 
indicating that the true nature of non-linearities in the business cycle is very important for what effects these non-linearities have on unit root tests. Finally, we briefly consider a model with Markov-switching autoregressive parameters. Such a model, with one regime an I(1) process and the other stationary, has been used by several authors, for example Ang and Bekaert (1998), to model interest rates. Standard tests have very low power against this process for empirically plausible parameterizations. In Section 3 we evaluate the performance of unit root tests when the true data generating process is I(1) in addition to the Markov-switching. The size distortions pointed out in the literature for a single break in trend growth rate or variance do not generalize to most parameterizations of Markov-switching. However, similar to the findings of Hecq (1995) for IGARCH errors, Markov-switching in variance can cause significant over-rejection in Perron-type tests that allow for a single structural break in level. Section 4 concludes.

\section{The Power of Unit Root Tests Against Regime-Switching Alternatives}

\subsection{Regime-Switching in the Trend Component}

In this section we investigate the power of unit root tests, including Perron-type tests, when the true process is $\mathrm{I}(0)$ conditional on a Markov-switching trend growth rate. To begin, consider the following data generating process:

$$
\begin{aligned}
& y_{t}=\tau_{t}+c_{t} \\
& \tau_{t}=\mu_{t}+\tau_{t-1} \\
& \mu_{t}=\mu_{1} S_{t}+\mu_{0}\left(1-S_{t}\right) \\
& \phi(L) c_{t}=\varepsilon_{t}, \varepsilon_{t} \sim \text { i.i.d. }\left(0, \sigma_{\varepsilon}^{2}\right)
\end{aligned}
$$

where $S_{t}$ is a discrete, unobserved state variable that takes on the value 0 or $1, \tau_{t}$ is a trend component with a switching growth rate, and $\phi(L)$ is a lag polynomial with either all roots outside the unit circle or one root on the unit circle and the rest outside. In this paper we consider 
the case where $S_{t}$ is first order Markov-switching. Here, the value of $S_{t}$ at time $t$ depends only on its value at time $t-1$, such that $P\left(S_{t}=1 \mid S_{t-1}=1\right)=p_{11}$ and $P\left(S_{t}=0 \mid S_{t-1}=0\right)=p_{00}$.

The model in (1) is a version of the models given in Hamilton (1989) and Lam (1990). In Hamilton (1989), one root of $\phi(L)$ is restricted to unity, that is $c_{t}$ has a stochastic trend. We will consider Hamilton's version of (1) in Section 3. Lam (1990) generalizes Hamilton's model to allow $c_{t}$ to (possibly) be a stationary autoregressive process. In this section we consider the performance of unit root tests in this case, where all roots of $\phi(L)$ lie outside the unit circle. Here, innovations do not have permanent effects in the periods between shifts in the growth rate of trend. For some intuition into how unit root tests will perform at distinguishing this model from the I(1) null, consider the alternative representation of the Markov trend function, $\tau_{t}$ :

$$
\tau_{t}=\tau_{0}+\mu_{0} * t+\left(\mu_{1}-\mu_{0}\right) \sum_{j=1}^{t} S_{j}
$$

Then, setting $\tau_{0}=0$ :

$$
\begin{aligned}
& y_{t}=\mu_{0} * t+R T_{t}+c_{t} \\
& R T_{t}=R T_{t-1}+\left(\mu_{1}-\mu_{0}\right) * S_{t}
\end{aligned}
$$

Here $y_{t}$ is written as the sum of a deterministic trend $\mu_{0} * t$, a stochastic component $R T_{t}$, and a stationary component, $c_{t}$. The stochastic component is introduced because the effects of the discrete shocks from the switching trend, $\left(\mu_{1}-\mu_{0}\right) * S_{t}$, are permanently reflected in the level of $R T_{t}$. This stochastic component is different from an integrated process in the traditional sense in that it does not necessarily change each period. It is similar to the integrated case in that first differencing $y_{t}$ eliminates the stochastic component, leaving only a Markov switching mean.

To assess the power of unit root tests against the process given in (2) we perform Monte 
Carlo simulations for both standard and Perron-type unit root tests. We parameterization the experiments based on the observation that the tests should do a poor job of identifying the alternative given by (2) when the proportion of the variance of changes in $y_{t}$ given by the stochastic component, $R S_{t}$, is smaller rather than larger. The variance of innovations to the stochastic component is given by $\left(\mu_{1}-\mu_{0}\right)^{2}\left(p-p^{2}\right)$ where $p=E\left(S_{t}=1\right)=\frac{1-p_{00}}{2-p_{00}-p_{11}}$. Lam (1990) finds that $37 \%$ of the variance of growth rates in real U.S. GNP is due to the stochastic component. We thus chose the following parameter values to yield this $37 \%$ proportion when $p_{11}=0.5$ and $p_{00}=0.95$, the transition probability estimates found by Lam: $\mu_{0}=1, \mu_{1}=-1.5, \sigma_{\varepsilon}^{2} \sim N(0,0.4)$, and $\phi(L)=1$. For each unit root test 1000 Monte Carlo simulations were performed with two sample sizes, $T=200$ and $T=500$ and the initial values of $S_{t}$ and $y_{t}$ set equal to zero. We consider the following values of $p_{11}: 0.5,0.6,0.7,0.8,0.9$, $0.95,0.98$ and of $p_{00}: 0.9,0.95,0.98$. These are based on a survey of the literature to find an empirically plausible range of transition probabilities.

\subsubsection{Augmented Dickey-Fuller Test}

In this section we consider the power of the Augmented Dickey Fuller, hereafter ADF, test [Dickey and Fuller (1979, 1981), Said and Dickey (1984)] against the alternative hypothesis given in (2). ${ }^{1}$ We consider the ADF test based on the t-statistic associated with the null hypothesis $\rho=1$ from the test regression:

$$
y_{t}=c+\rho y_{t-1}+\beta t+\sum_{j=1}^{k} \phi_{j} \Delta y_{t-j}+\eta_{t}
$$

\footnotetext{
${ }^{1}$ Detailed descriptions of all tests considered in this paper are provided in Piger (2000).
} 
with the lag length, $k$, chosen by the backward lag-length selection procedure given in Campbell and Perron (1991) with a maximum lag-length, $\bar{k}$, set equal to the lower integer bound of $T^{1 / 3}$ as suggested by Said and Dickey (1984).

As would be expected from the received literature the ability of the ADF tests to distinguish the regime-switching trend stationary alternative given in (2) is quite poor. Tables 1-2 show the rejection probabilities for the $5 \%$ nominal size ADF test. For the $T=200$ case the test never rejects above $35 \%$, only rejects above $20 \%$ for 6 of the 21 combinations of the transition probabilities considered, and often rejects in the 5-10\% range. The test tends to perform better when one transition probability dominates the other, for example, for the values of the transition probabilities estimated by Lam (1990) for U.S. real GDP, $p_{00}=.95$ and $p_{11}=0.5$, the test rejects with a $31 \%$ frequency. This is because the variance of innovations to the stochastic component, $R T_{t}$, is smaller the larger the difference between the transition probabilities, that is $\left(\mu_{1}-\mu_{0}\right)^{2}\left(p-p^{2}\right)$ is a decreasing function of $\left|p_{00}-p_{11}\right|$. Interestingly this is not the case where there are the fewest number of breaks, which would occur when $p_{00}=0.98$ and $p_{11}=0.98$. For the larger sample size the ADF test has even lower power, rejecting at a less than $10 \%$ frequency in all cases. This is not surprising as the larger sample size gives the ADF test more opportunity to detect the stochastic component, $R T_{t}$.

\subsubsection{Perron-Type Tests}

Since the influential work of Perron (1989) a large number of unit root tests that allow for structural breaks in trend growth rate or level under the alternative have been developed. The objective of this research program is to develop tests with higher power against broken-trend stationary alternatives. The tests are robust to a pre-specified number of structural breaks, usually 
one. However, there has been some argument in the literature that when there are multiple structural breaks in trend growth rate it may be sufficient to simply account for the largest of these breaks, see for example Garcia and Perron (1996), pg. 113. We are thus interested in whether such tests provide increased power against an alternative with a Markov-switching trend growth rate. Here we consider two such tests that assume a single break in the growth rate of the trend function occurring at an unknown date, one given in Perron $(1994,1997)$, hereafter the Perron test, and the other given in Zivot and Andrews (1992), hereafter the ZA test. The Perron test assumes a single break in trend growth rate under both the null and alternative hypothesis, and specifies the break as an "additive outlier" meaning the full effects of the break is immediately reflected. The test is based on the regressions in equations (3a) and (3b) of Perron (1997). The ZA test assumes a single break in trend growth rate under only the alternative hypothesis and specifies the break as an "innovational outlier", meaning the full effects of the change are felt over time. The test is based on the regression in equation 2' in Zivot and Andrews (1992). For both tests the date of the structural break was estimated as the date that provides the most evidence against the null hypothesis, see Zivot and Andrews (1992) for details.

Tables 3-6 contain the rejection frequencies for 5\% nominal size Perron and ZA tests. Interestingly, the Perron test provides no obvious improvement over the ADF test. For example, when $T=200$ the ADF test rejects more frequently for 17 of the 21 combinations of transition probabilities considered. For the transition probabilities estimated by Lam (1990) for real GDP, $p_{00}=.95$ and $p_{11}=0.5$, the Perron test rejects $16 \%$ of the time vs. $31 \%$ for the ADF test. The ZA test performs somewhat better, rejecting more frequently than the ADF test for 18 of the 21 combinations of transition probabilities considered when $T=200$. However, the difference is not decisive: in 10 of these 18 cases the ZA test is within $15 \%$ of the ADF test. In addition, the 
ZA test only rejects more than $40 \%$ of the time on three occasions and for over half the cases rejects at a less than $25 \%$ frequency. For the Lam (1990) transition probability estimates for real GDP the ZA test rejects at a $19 \%$ frequency vs. $31 \%$ for the ADF test. When $T=500$ the tests have even lower power, usually rejecting at close to their nominal size.

\subsection{Regime-Switching in the Transitory Component}

Two-state Markov-switching in trend growth rate, such as the model discussed in the previous section, has been used extensively to model business cycle asymmetry. One reason for its popularity is the ability of a regime switching trend growth rate to capture the empirical observation that recessions are steeper and shorter than expansions. However, one implication of the two-state Markov-switching trend model is that recessions have permanent effects on the level of output, that is the economy never recovers output lost during a recession. Many authors have provided evidence that this implication is not consistent with the data, instead, following steep, short recessions the economy seems to undergo a high-growth recovery phase to gain back what was lost, see for example Friedman (1964, 1993), Wynne and Balke (1992, 1996), and Sichel (1994). In other words, the business cycle is better characterized with three phases rather than two. Recently, Kim and Nelson (1999) used Markov regime-switching in the transitory component of real GDP to capture this pattern of business cycle asymmetry. Here we consider a trend stationary version of their model:

$$
\begin{aligned}
& y_{t}=\tau_{t}+c_{t} \\
& \tau_{t}=\mu+\tau_{t-1} \\
& \phi(L) c_{t}=\gamma S_{t}+\varepsilon_{t}, \varepsilon_{t} \sim \text { i.i.d. }\left(0, \sigma_{\varepsilon}^{2}\right)
\end{aligned}
$$

where $\phi(L)$ has all roots outside the unit circle. Here, unlike the model in (1), the average growth rate of the deterministic trend, $\mu$, is constant. Instead, regime switching occurs in the transitory component, $c_{t}$. If $\gamma<0$, when $S_{t}=1$ the level of the series is driven down into a 
steep recession. However, the recession is not permanent as past shocks from $\gamma$ disappear through the autoregressive dynamics in the transitory component, causing a "high growth recovery phase" once $S_{t}$ returns to zero. In the words of Friedman(1964), the economy is "plucked" downward during recession, bouncing back to trend following the recession.

The results of Kim and Nelson (1999) suggest that a model specifying recessions as "plucking" episodes provides as good as or better description of U.S. real GDP than a model with regime shifts in the trend component. However, given that the regime switching in (4) works through the transitory component we would expect unit root tests to have much better power against this alternative that the model in section 2.1. To investigate this we perform a Monte Carlo experiment with the ADF test. We parameterize the simulation based on the percentage of the variance of $c_{t}$ coming from the "plucks" $\gamma$. Kim and Nelson (1999) find this percentage to be approximately $80 \%$ for real GDP for estimated transition probabilities of $p_{11}=.95$ and $p_{00}=.70$. When $\phi(L)=1$ this percentage is:

$\frac{\gamma^{2}\left(p-p^{2}\right)}{\gamma^{2}\left(p-p^{2}\right)+\sigma_{\varepsilon}^{2}}$

To meet the $80 \%$ metric we parameterize the simulation with $\gamma=-1.0$ and $\varepsilon_{t} \sim N(0, .04)$. We set $\mu=0.8$, the average growth rate of real GDP over the Kim and Nelson sample. Again, we perform 1000 Monte Carlo trials for the same range of transition probabilities as in Section 2.1.

Tables 7-8 contains the rejection frequencies for the 5\% ADF test. As expected, the ADF test performs very well, rejecting at close to $100 \%$ for the most empirically relevant values of the transition probabilities. For example, for the estimated transition probabilities found by Kim and Nelson for real GDP, $p_{11}=.95$ and $p_{00}=.70$, the ADF test rejects at a $99 \%$ frequency when $T=200$ and a $100 \%$ frequency when $T=500$. The test does have lower power the larger both 
transition probabilities become, that is the smaller the number of "plucking" episodes. However, the power remains above $50 \%$ in all but one of the 21 combinations considered for $T=200$ and in all cases for $T=500$.

The differing performance of unit root tests for the model in (1) vs. the model in (4) is important in answering the question of whether real GDP has a unit root. If we believe that business cycle non-linearities are shifts in trend as in Lam (1990) these shifts will have significant deleterious effects on the power of unit root tests, including Perron-type tests. If however, these non-linearities are better characterized as Friedman's "plucks" the power of unit root tests will be unaffected. Instead, the only sort of structural change relevant to unit root tests left will be long run breaks, such as the much discussed productivity slowdown. In this case Perron-type tests will still have an advantage over standard tests such as the ADF test. This points us to the importance of determining the true nature of business cycle non-linearities for deciding what classes of unit root tests should be used.

\subsection{Regime-Switching Autoregressive Coefficients}

To this point we have investigated Markov-switching taking the form of discrete disturbances to the trend or transitory component of a time series. Another popular formulation is Markovswitching in the autoregressive parameters of a time series, an example of which is: ${ }^{2}$

$$
\begin{aligned}
& y_{t}=\mu_{t}+\rho_{t} y_{t-1}+\varepsilon_{t} \\
& \mu_{t}=\mu_{1} S_{t}+\mu_{0}\left(1-S_{t}\right) \\
& \rho_{t}=\rho_{1} S_{t}+\rho_{0}\left(1-S_{t}\right) \\
& \varepsilon_{t} \sim \text { i.i.d. }\left(0, \sigma_{\varepsilon t}^{2}\right) \\
& \sigma_{\varepsilon t}^{2}=\sigma_{\varepsilon 1}^{2} S_{t}+\sigma_{\varepsilon 0}^{2}\left(1-S_{t}\right)
\end{aligned}
$$

\footnotetext{
${ }^{2} \mathrm{We}$ are indebted to an anonymous referee for suggesting this experiment.
} 
In (6), $y_{t}$ follows an $\mathrm{AR}(1)$ process in which the autoregressive parameter, the constant term, and the variance of the error term all switch between two regimes. A popular version of (6) in the empirical literature specifies $y_{t}$ to be $\mathrm{I}(1)$ in one regime and $\mathrm{I}(0)$ in the other, for example $\rho_{0}=1$ and $\left|\rho_{1}\right|<1$. Ang and Bekaert (1998) demonstrate that as long as the $\mathrm{I}(0)$ regime has positive probabilities of occurring and persisting, in this case $\left(1-p_{00}\right) \neq 0$ and $p_{11} \neq 0, y_{t}$ is covariance stationary. This "occasionally integrated" model has been usefully employed to model interest rates. For example, Ang and Bekaert (1998) point out that the U.S. Federal Reserve tends to move short term interest rates in a very persistent fashion during low inflation periods. However, during high inflation times Federal Reserve interest rate changes become less persistent and have higher variance.

For our purposes, we are interested in the ability of unit root tests to distinguish the occasionally integrated model from the I(1) null hypothesis. To investigate this issue we performed Monte Carlo simulations with the ADF test when the generating process is (6). We parameterize the Monte Carlo experiments to mimic the pattern of Federal Reserve interest rate movements discussed above. Thus, when $S_{t}=0$ (low inflation times) $y_{t}$ is a random walk with no drift, that is $\rho_{0}=1, \mu_{0}=0$, and $\varepsilon_{t} \mid S_{t}=0 \sim N(0, .25)$. When $S_{t}=1$ (high inflation times) $y_{t}$ is a stationary $\operatorname{AR}(1)$ with positive mean and $\varepsilon_{t} \mid S_{t}=1 \sim N(0,2.0)$. One would expect that unit root tests would perform worse for more persistent values of the autoregressive parameter when $S_{t}=1$. Thus, we consider three pairs of $\mu_{1}, \rho_{1}:(1.0,0.8) ;(0.5,0.9) ;(0.25,0.95)$. In these pairs $\mu_{1}$ is altered to maintain a constant mean of 5 for $y_{t}$ in the stationary state.

Tables 9-13 present the Monte Carlo simulations for the three pairings of $\mu_{1}, \rho_{1}$ and the sample sizes $T=200$ and $T=500$. As would be expected, the tests perform better as $\rho_{1}$ 
decreases, as $p_{11}$ increases relative to $p_{00}$ (the less time that is spent in the I(1) state), and the larger the sample size (the more data available for the test to detect the $\mathrm{I}(0)$ state). In general however the tests perform very poorly for empirically plausible parameterizations. For example, for the $T=200$ cases (Figures 9,11, and 13) the tests only reject above 50\% on 3 occasions (all for the smallest value of $\rho_{1}$ ), and only reject above $20 \%$ on 16 occasions, 9 of these for the smallest value of $\rho_{1}$. As the sample size increases the performance of the test is fairly good for the lowest value of $\rho_{1}$ but is still poor for larger values of $\rho_{1}$. For example, Ang and Bekaert (1998) show that the regime switches in U.S. interest rates roughly correspond to business cycle frequencies. Depending on the frequency of the data this corresponds to values of $p_{00}$ between 0.9 and 0.95 and values of $p_{11}$ between 0.5 and 0.9 . For $\rho_{1}=.9$ and $T=500$ the ADF test only rejects above $40 \%$ for this range of transition probabilities on one occasion.

\section{Regime-Switching I(1) Processes and the Size of Unit Root Tests}

\subsection{Regime-Switching in the Trend Component and Variance}

In Section 2.1 we were interested in the ability of unit root tests to distinguish a process that was I(0) with a Markov-switching trend growth rate from an I(1) process. Here we will investigate what deleterious size effects a Markov-switching trend growth rate and variance in an

otherwise I(1) process might have on unit root tests. Consider the following model motivated by Hamilton (1989):

$$
\begin{aligned}
& y_{t}=\tau_{t}+c_{t} \\
& \tau_{t}=\mu_{t}+\tau_{t-1} \\
& \mu_{t}=\mu_{0}\left(1-S_{t}\right)+\mu_{1} S_{t} \\
& \phi(L) c_{t}=\varepsilon_{t}, \varepsilon_{\mathrm{t}} \sim \text { i.i.d. }\left(0, \sigma_{\varepsilon t}^{2}\right) \\
& \sigma_{\varepsilon t}^{2}=\sigma_{\varepsilon 1}^{2} S_{t}+\sigma_{\varepsilon 0}^{2}\left(1-S_{t}\right)
\end{aligned}
$$


Again, $S_{t}$ is first order Markov-switching and $\tau_{t}$ is a deterministic trend component with a switching growth rate. As in Hamilton (1989) we specify $\phi(L)$ to have one root on the unit circle and all other roots outside the unit circle, so that shocks to $y_{t}$ in between the Markov-switching trend breaks have permanent effects on the level of the series. We also allow the variance of the error term to undergo regime switching.

To simplify matters we set $\phi(L)=(1-L)$. The model in (7) can then be written with a constant growth rate and serially correlated, conditionally heteroskedastic errors:

$$
\begin{aligned}
& \Delta y_{t}=\mu+e_{t} \\
& e_{t}=\left(\mu_{1}-\mu\right) S_{t}+\left(\mu_{0}-\mu\right)\left(1-S_{t}\right)+\varepsilon_{t}
\end{aligned}
$$

To make $E\left(e_{t}\right)=0$ choose $\mu=\left(\mu_{1}-\mu_{0}\right) p+\mu_{0}$. Substituting in the chosen expression for $\mu$ we arrive at the autocovariance function:

$$
\operatorname{Cov}\left(e_{t}, e_{t-k}\right)=\left(\mu_{1}-\mu_{0}\right)^{2} E\left(S_{t}-p\right)\left(S_{t-k}-p\right)=\left(\mu_{1}-\mu_{0}\right)^{2} \operatorname{Cov}\left(S_{t}, S_{t-k}\right)
$$

Also, conditional on $S_{t}, e_{t}$ is heteroskedastic due to the switching variance in (7):

$$
E\left(e_{t}^{2} \mid S_{t}=j\right)=\sigma_{\varepsilon j}^{2}, j=0,1
$$

A result from the theory of Markov processes tells us that $P\left(S_{t}=1 \mid S_{t-k}=1\right)$ and $P\left(S_{t}=0 \mid S_{t-k}=0\right)$ converge to the unconditional probabilities $p$ and (1- $\left.p\right)$ at a geometric rate. Then, noting that $\operatorname{Cov}\left(S_{t} S_{t-k}\right)=\left(p^{*} P\left(S_{t}=1 \mid S_{t-k}=1\right)-p^{2}\right)$ we have $\operatorname{Cov}\left(e_{t}, e_{t-k}\right)=$ $\left(\mu_{1}-\mu_{0}\right)^{2}\left(p^{*} P\left(S_{t}=1 \mid S_{t-k}=1\right)-p^{2}\right) \rightarrow 0$ geometrically. Thus, the model in (7) can be written with constant trend growth rate and errors exhibiting serial correlation that dies off geometrically. It should be noted that this result is entirely due to the modeling of breaks in the trend function as endogenous, probabilistic events. It does not hold true in models assuming a 
pre-determined number of structural breaks in trend growth rate such as the cases considered by Perron (1989) and Zivot and Andrews (1992) among others.

Several previous studies, for example Schwert (1989a), investigate the properties of unit root tests under various forms of ARMA innovations. Therefore, we will find an ARMA process a useful alternative representation of $e_{t}$. Consider the following stationary AR(1) representation of $S_{t}$ given by Hamilton (1989):

$S_{t}=\left(1-p_{00}\right)+\theta S_{t-1}+\omega_{t}$ $\theta=-1+p_{00}+p_{11}$

where, conditional on $S_{t-1}=1, \omega_{t}=\left(1-p_{11}\right)$ with probability $p_{11}$ and $\omega_{t}=-p_{11}$ with probability $1-p_{11}$ and conditional on $S_{t-1}=0, \omega_{t}=-\left(1-p_{00}\right)$ with probability $p_{00}$ and $\omega_{t}=p_{00}$ with probability $1-p_{00}$. Hamilton (1989) shows that the error term, $\omega_{t}$, has $E\left(\omega_{t}=0\right), E\left(\omega_{t}^{2}\right)=\sigma_{\omega}^{2}=p_{11}\left(1-p_{11}\right) p+p_{00}\left(1-p_{00}\right)(1-p)$, and is uncorrelated in that $E\left(\omega_{t} \mid \omega_{t-j}\right)=0$ for all four possible values of $\omega_{t-j}$ and $j=1,2, \ldots{ }^{3}$. Using (11) note that:

$$
\begin{aligned}
& e_{t}-\theta e_{t-1}=d+b \omega_{t}+v_{t}-\theta v_{t-1} \\
& d=\left(\mu_{1}-\mu\right)\left(1-p_{00}\right)+\left(\mu_{0}-\mu\right)\left(1-p_{11}\right) \\
& b=\left(\mu_{1}-\mu_{0}\right)
\end{aligned}
$$

The term on the left hand side of (12) is an AR(1) while the term on the right hand side has the autocovariance function of an $\mathrm{MA}(1)$ in that it is zero after the first lag. Thus, $e_{t}$ follows an $\operatorname{ARMA}(1,1)$ process.

\footnotetext{
${ }^{3}$ However, as Hamilton (1989) points out, $\omega_{t}$ is not statistically independent of lagged values of $\omega_{t}$ in that $\omega_{t}^{2}$ is forecastable based on past knowledge of the state $S_{t}$. Statistical independence is not required for the moving average representation given in (12).
} 
To determine the effects of the regime switching in trend growth rate and variance on unit root tests we perform Monte Carlo experiments for the three tests discussed in Section 2: the ADF test, Perron test, and ZA test. We consider two cases, one in which there is only regime switching in trend growth rate and one in which there is only switching in variance. To parameterize the trend switching case we set the parameters to yield a specified amount of serial correlation as measured by the first order autocorrelation of $e_{t}$ :

$$
\operatorname{corr}\left(e_{t}, e_{t-1}\right)=\frac{\left(\mu_{1}-\mu_{0}\right)^{2}\left(p^{*} p_{11}-p^{2}\right)}{\left(\mu_{1}-\mu_{0}\right)^{2}\left(p-p^{2}\right)+p \sigma_{v 1}^{2}+(1-p) \sigma_{v 0}^{2}}
$$

where the denominator is the unconditional variance of $e_{t}$. We set $\mu_{0}=1, \mu_{1}=5$, $\varepsilon_{t} \sim N\left(0, \sigma_{v t}^{2}\right)$, and $\sigma_{v 0}=\sigma_{v 1}=1$ to yield a value of (13) equal to 0.50 for $p_{11}=0.9$ and $p_{00}=0.7$, the transition probability estimates for U.S. real GNP found by Hamilton (1989). This level of autocorrelation is similar to that found in the received literature. For example, the value of (13) for U.S. real GNP reported by Hamilton is 0.38 while Engel's (1994) parameter estimates for the Japanese / French exchange rate suggest a value of (13) equal to 0.50 .

For the variance switching case we set $\varepsilon_{t} \sim N\left(0, \sigma_{v t}^{2}\right), \frac{\sigma_{v 1}}{\sigma_{v 0}}=\frac{3}{1}$, and $\mu_{0}=\mu_{1}=1.0$. This level of heteroskedasticity is quite reasonable for asset prices, for example Turner, Startz, and Nelson (1989) report $\frac{\sigma_{v 1}}{\sigma_{v 0}}=2.6$ for stock returns while Engel (1994) reports much higher ratios for several U.S. exchange rates. However, this level of heteroskedasticity is overstated for series such as real GDP. Thus, our results for the switching variance case have more relevance for financial time series than for macroeconomic quantities. Again, we consider the same range of 
transition probabilities and sample sizes as in Section 2. Each Monte Carlo experiment is comprised of 1000 trials with initial values of $S_{t}$ and $y_{t}$ set equal to zero.

We begin by considering the effects of the Markov-switching trend growth rate in (7). Because this regime-switching simply introduces serial correlation into an otherwise I(1) process we can appeal to the large literature evaluating the effects of serial correlation on unit root tests. Schwert (1989) demonstrates the ADF test performs well in the presence of ARMA errors such as those in (12). However, Leybourne, Mills, and Newbold (1998) show that the ADF test tends to over-reject the null hypothesis when there is a single break in trend growth rate that occurs early in the sample. Thus, we expect the ADF test to over-reject for parameterizations of (7) that yield few breaks, with one occurring early in the sample. The question of interest is for how broad a range of the Markov-switching parameterizations this result holds. Tables 15 and 16 present the rejection frequencies for the 5\% ADF test. Note that only for the $T=200$ case and a value of $p_{11}=0.98$ are the size distortions pointed out by Leybourne, Mills, and Newbold present. For most parameterizations the ADF test has size close to its nominal size and in general is slightly oversized. This is likely due to the Campbell-Perron lag selection procedure which has been documented by Hall (1994) to cause slight over-rejection ${ }^{4}$.

Next we consider the Perron and ZA test that allow for a single break in trend growth rate under the alternative. Tables 17-18 contain the rejection frequencies for the 5\% Perron test. The Perron test performs similarly to the ADF test for most parameterizations, which is not surprising given that it captures serial correlation in the same way as the ADF test. The Perron test performs better than the $\mathrm{ADF}$ test when $p_{11}=0.98$, thus it is not subject to the Leybourne, Mills and

\footnotetext{
${ }^{4}$ We also considered SIC lag selection for the ADF test. The results were quantitatively similar and are detailed in Piger (2000).
} 
Newbold (1998) critique. This is because the Perron test is robust to a single break in trend growth rate under the null hypothesis as well as the alternative. Figures 19-20 demonstrate that the ZA test can be significantly oversized when there are only a small number of breaks, that is for large values of $p_{00}$ or $p_{11}$. This is because the distribution of the ZA test is derived assuming a null with no structural change, the presence of a small number of structural breaks under the null hypothesis will violate this null hypothesis and lead to over-rejections. This issue is not as serious for the larger sample size, $T=500$. Both the Perron and ZA test perform similarly to the ADF tests for this larger sample size.

We now move to the simulations investigating Markov-switching in variance. Many authors have investigated the effects of various forms of heteroskedasticity on unit root tests, including Pantula (1988), Kim and Schmidt (1993), and Seo (1999). Provided that the heteroskedasticity meets certain conditions, given explicitly by Hamori and Tokihisa (1997), heteroskedasticity does not create size distortions for standard unit root tests. In Piger (2000) it is shown that Markov-switching heteroskedasticity meets these conditions, suggesting that standard unit root tests should perform well. However, we are still interested in investigating two scenarios. First, Hamori and Tokihisa (1997) have shown that a single break in variance causes Dickey-Fuller type tests to be oversized. Thus, we might expect that certain parameterizations of Markovswitching in variance that yield a small number of breaks will cause size distortions in the ADF test. Tables 21-22 demonstrate that this is not the case. The ADF test is reasonably sized for even large values of $p_{00}$ and $p_{11}$, suggesting the result of Hamori and Tokihisa fades quickly when more than one break is allowed.

Secondly, Hecq (1995) points out for the case of IGARCH errors that periods of high and low variance in an integrated process can lead to the illusion of breaks in the level of trend. Tests 
that are robust to a structural break in level under the alternative can spuriously detect such breaks and over-reject as a result. We thus might expect versions of the Perron and ZA test that allow for break in the level of trend to be oversized in the presence of Markov-switching heteroskedasticity. To investigate this issue we consider the performance of the Perron test allowing for a single break in the level of trend under both the null and the alternative, based on equations (14) and (17) in Perron (1994), and the ZA test allowing for a single break in the level of trend under the alternative, given by equation 1' in Zivot and Andrews (1992). As Figures 2326 point out, the size distortions can be significant for certain parameterizations of $p_{00}$ and $p_{11}$. For example, for $T=200$ the 5\% nominal size Perron test rejects at greater than $10 \%$ in all but one of the 21 combinations of transition probabilities considered and greater than $15 \%$ for 8 of the 21 combinations. The ZA test rejects at greater than $10 \%$ in all but 2 cases and greater than $15 \%$ in 13 cases when $T=200$. Both tests perform somewhat better in the $T=500$ case but are still oversized.

\subsection{Regime-Switching in the Transitory Component}

In Section 2.2 we discussed how different Markov-switching models of business cycle asymmetry can have very different implications for the effects of asymmetry on the power of unit root tests. Here we examine the difference this modeling choice has for the size of unit root tests. Consider the following I(1) version of the model presented in Section 2.2:

$$
\begin{aligned}
& y_{t}=\tau_{t}+z_{t}+c_{t} \\
& \tau_{t}=\mu+\tau_{t-1} \\
& z_{t}=z_{t-1}+v_{t}, v_{\mathrm{t}} \sim \text { i.i.d. }\left(0, \sigma_{v}^{2}\right) \\
& \phi(L) c_{t}=\gamma S_{t}+\varepsilon_{t}, \varepsilon_{\mathrm{t}} \sim \text { i.i.d. }\left(0, \sigma_{\varepsilon}^{2}\right)
\end{aligned}
$$

where $\phi(L)$ has all roots outside the unit circle. Here $y_{t}$ is the sum of a deterministic trend with constant drift, a random walk component, and a stationary autoregressive component that, 
assuming $\gamma<0$, is "plucked" downward whenever $S_{t}=1$. To see the effects the process in (14) might have on the size of unit root tests rewrite (14) in first differences assuming $\phi(L)=1$ :

$$
\begin{aligned}
& \Delta y_{t}=\mu+e_{t}^{*} \\
& e_{t}^{*}=v_{t}+\Delta \varepsilon_{t}+\gamma \Delta S_{t}
\end{aligned}
$$

The process can thus be written in first differences with constant drift and an error term that is augmented by a Markov-switching component. The Markov-switching introduces additional serial correlation into the process, namely the first difference of $S_{t}$. One interesting note is the similarity of this case to the "additive outlier" literature discussed by Franses and Haldrup (1994) among others. The parameter $\gamma$ would correspond to an additive outlier in the case where $S_{t}$ was serially uncorrelated as opposed to being a Markov-switching process. As Madalla and Yin (1997) and Vogelsang (1999) point out, the first difference of $S_{t}$ in (15) would then introduce an $\mathrm{MA}(1)$ component into the first difference of $y_{t}$. For smaller values of $\gamma$ the additional serial correlation introduced in both the Markov-switching and additive outlier cases is captured by tests such as the ADF test and does not cause over-rejections. However, as the size of $\gamma$ increases, the contribution of the transitory component to the variance of $\Delta y_{t}$ increases relative to the contribution of the trend component. This can eventually lead to spurious rejections from unit root tests if the variance of the transitory component begins to dominate. The question this is the case for parameterizations of (14) corresponding to U.S. business cycles.

To investigate this issue we performed Monte Carlo experiments to investigate the performance of the ADF tests when the generating process is (14). We parameterize the simulation using parameter estimates from Kim and Nelson (1999) for U.S. real GDP. That is, we set $\mu=.8, v_{t} \sim N(0,0.4), \gamma=-1.1, \varepsilon_{t} \sim N(0,0.04)$, and the lag order of $\phi(L)$ set equal to 
2 with $\phi_{1}=1.26$ and $\phi_{2}=-0.46$. Tables 27 and 28 demonstrate that this level of "plucking" is indeed large enough to cause spurious rejections in the ADF test. These rejections are fairly severe, for both $T=200$ and $T=500$ the $5 \%$ ADF test rejects more than $10 \%$ of the time for all combinations of the transition probabilities considered. For $T=200$ the rejections climb above $30 \%$ for 9 of the 21 cases while for $T=500$ rejections are larger than $30 \%$ on 8 occasions. Again, this points out that whether non-linearities in the U.S. business cycle take the form of shifts in trend or "plucks" in the transitory component can have large implications for the performance of unit root tests applied to U.S. output series.

\section{Conclusion}

For the past 20 years researchers have shown great interest in whether economic time series are $\mathrm{I}(1)$ or $\mathrm{I}(0)$. The primary tools in these investigations are a battery of unit root tests. At the same time there is a growing consensus that many economic and financial time series undergo structural change that is modeled with much success by an endogenous Markov-switching state variable. We have investigated the performance of unit root tests in the face of various types of Markov regime-switching when the true process is $\mathrm{I}(0)$ and $\mathrm{I}(1)$ in the periods between the regime-switching. Our main findings are:

1) In line with previous literature, the Augmented Dickey-Fuller test does a poor job of distinguishing an $\mathrm{I}(0)$ process with Markov-switching breaks in trend growth rate from an I(1) process. Interestingly however, tests designed to be robust to a single structural break in trend growth rate under the alternative also have very low power in this case.

2) When the true process is I(1) and undergoes Markov-switching in both trend growth rate and variance ADF tests have approximately the correct size for almost all combinations 
of transition probabilities. This demonstrates that studies documenting size distortions from a single break in trend growth and variance do not generalize to multiple, probabilistic breaks. Also, tests robust to a single break in level over-reject the null hypothesis when there is Markov-switching in variance.

3) When modeling business cycle asymmetry, an alternative to Markov-switching in trend growth rate as in Lam (1990) is to allow for Markov-switching "plucks" in the transitory component of GDP as in Kim and Nelson (1999). The ADF test has good power when these "plucks" occur under the alternative hypothesis. However, the ADF test can be oversized when the regime-switching occurs under the null, mainly because the "plucks" increase the contribution of the transitory component to the series. This demonstrates that the true nature of business cycle asymmetry has serious implications for the performance of unit root tests on output series.

\section{References}

Ang, A., and Bekaert, G. (1998), "Regime Switches in Interest Rates," Working Paper, NBER.

Balke, N.S., and Fomby, T.B. (1991), "Shifting Trends, Segmented Trends and Infrequent Permanent Shocks," Journal of Monetary Economics, 28, 61-85.

Banerjee, A., Lumsdaine, R.L., and Stock, J.H. (1992), "Recursive and Sequential Tests for a Unit Root: Theory and International Evidence," Journal of Business and Economic Statistics, $10,271-287$.

Barber, C., Robertson, D., and Scott, A. (1997), "Property and Inflation: The Hedging Characteristics of UK Commercial Property, 1967-1994," Journal of Real Estate Finance, $15,59-76$.

Campbell, J.Y., and Perron, P. (1991), "Pitfalls and Opportunities: What Macroeconomics Should Know about Unit Roots," NBER Macroeconomics Annual, 141-201.

Cecchetti, S.G., and Mark, N.C. (1990), "Evaluating Empirical Tests of Asset Pricing Models Alternative Interpretations," American Economic Review, 80, 48-51. 
Christiano, L.J. (1992), "Searching for a Break in GNP," Journal of Business and Economic Statistics, 10, 237-250.

Dickey, D.A., and Fuller, W.A. (1979), "Distribution of the Estimators for Autoregressive Time Series with a Unit Root," Journal of the American Statistical Association, 74, 427-31.

Driffill, J., and Sola, M. (1998), "Intrinsic Bubbles and Regime-Switching," Journal of Monetary Economics, 42, 357-373.

Dueker, M., and Fischer, A.M. (1996), "Inflation Targeting in a Small Open Economy: Empirical Results for Switzerland," Journal of Monetary Economics, 37, 89-103.

Engel, C. (1994), "Can the Markov Switching Model Forecast Exchange Rates?," Journal of International Economics, 36, 151-165.

Evans, M.D.D., and Lewis, K.K. (1993), "Trend in Excess Returns in Currency and Bond Markets," European Economic Review, 37, 1005-1019.

Evans, M.D.D., and Wachtel, P. (1993), "Were Price Changes During the Great-Depression Anticipated? Evidence from Nominal Interest Rates," Journal of Monetary Economics, 32, 3-34.

Franses, P.H., and Haldrup, N. (1994), "The Effects of Additive Outliers on Tests for Unit Roots and Cointegration," Journal of Business and Economic Statistics, 12, 471-478.

Friedman, M. (1964), Monetary Studies of the National Bureau, the National Bureau Enters its $45^{\text {th }}$ Year, $44^{\text {th }}$ Annual Report, 7-25, New York: NBER, Reprinted in Friedman, M. (1969), The Optimum Quantity of Money and Other Essays, Chicago: Aldine.

Friedman, M. (1993), “The "Plucking Model” of Business Fluctuations Revisited," Economic Inquiry, 31, 171-177.

Garcia, R., and Perron, P. (1996), "An Analysis of the Real Interest Rate under Regime Shifts," Review of Economics and Statistics, 78, 111-125.

Hall, A. (1994), "Testing for a Unit Root in Time Series with Pretest Data-Based Model Selection," Journal of Business \& Economic Statistics, 12, 461-470.

Hall, S., Psaradakis, Z. and Sola, M. (1997), "Cointegration and Changes in Regime: The Japanese Consumption Function," Journal of Applied Econometrics, 12, 151-168.

Hamilton, J.D. (1989), "A New Approach to the Economic Analysis of Non-stationary Time Series and the Business Cycle," Econometrica, 57, 357-384.

Hamori, S., and Tokihisa, A. (1997), "Testing for a Unit Root in the Presence of a Variance Shift," Economics Letters, 57, 245-253. 
Hecq, A. (1995), "Unit Root Tests with Level Shift in the Presence of GARCH," Economics Letters, 49, 125-130.

Kim, C.-J., and Nelson, C.R. (1999), “Friedman's Plucking Model of Business Fluctuations: Tests and Estimates of Permanent and Transitory Components," Journal of Money, Credit and Banking, 31, 317-34.

Kim, K., and Schmidt, P. (1993), "Unit Root Tests with Conditional Heteroskedasticity," Journal of Econometrics, 59, 287-300.

Lam, P.-S. (1990), "The Hamilton Model with a General Autoregressive Component," Journal of Monetary Economics, 26, 409-432.

Leybourne, S.J., Mills, T.C., and Newbold, P. (1998), "Spurious Rejections by Dickey-Fuller Tests in the Presence of a Break Under the Null," Journal of Econometrics, 87, 191-203.

Lumsdaine, R.L., and Papell, D.H. (1997), "Multiple Trend Breaks and the Unit Root Hypothesis," The Review of Economics and Statistics, 79, 212-218.

Maddala, G.S. and Y. Yin (1997), "Outliers, Unit Roots and Robust Estimation of Nonstationary Time Series," in G.S. Maddala and C.R. Rao (eds.) Handbook of Statistics, Vol 15, 237-266.

Nelson, C.R., and Plosser, C.I. (1982), “Trends and Random Walks in Macroeconomic Time Series: Some Evidence and Implications,” Journal of Monetary Economics, 10, 139-162.

Pantula, S.G. (1988), "Estimation of Autoregressive Models with ARCH Errors," Sankhya B, 50, 119-138.

Perron, P. (1989), "The Great Crash, the Oil Price Shock and the Unit Root Hypothesis," Econometrica, 57, 1361-1401.

Perron, P. (1990), "Testing for a Unit Root in a Time-Series with a Changing Mean," Journal of Business and Economic Statistics, 8, 153-162.

Perron, P. (1994), "Trend, Unit Root and Structural Change in Macroeconomic Time Series," In Cointegration for the Applied Economist, ed. B.B. Rao, New York: St. Martin's Press, pp. 113-146.

Perron, P. (1997), "Further Evidence on Breaking Trend Functions in Macroeconomic Variables," Journal of Econometrics, 80, 355-385.

Phillips, P.C.B., and Xiao, Z. (1998), “A Primer on Unit Root Testing,” Journal of Economic Surveys, 12, 423-470.

Piger, J. (2000), "Essays on Business Cycle Asymmetry," Ph.D. Dissertation, University of Washington. 
Raymond, J.E., and Rich, R.W. (1997), "Oil and the Macroeconomy: A Markov State-Switching Approach, Journal of Money, Credit and Banking, 29, 193-213.

Rugemurcia, F.J. (1995), “Credibility and Changes in Policy Regime.” Journal of Political Economy, 103, 176-208.

Said, S.E., and Dickey, D.A. (1984), "Testing for Unit Roots in Autoregressive-Moving Average Models of Unknown Order," Biometrika, 71, 599-607.

Schwert, W.G. (1989a), “Tests for Unit Roots: A Monte Carlo Investigation,” Journal of Business and Economic Statistics, 7, 147-159.

Schwert, W.G. (1989b), "Why Does Stock Market Volatility Change Over Time?" Journal of Finance, 44, 1115-1153.

Schwert, W.G. (1996), "Business Cycles, Financial Crises and Stock Volatility". In Stock Market Crashes and Speculative Manias, ed. E.N. White, Cheltenham, U.K.: Elgar, pp. 231-73.

Seo, B. (1999), "Distribution Theory for Unit Root Tests with Conditional Heteroskedasticity,". Journal of Econometrics, 91, 113-144.

Sichel, D. E. (1994), "Inventories and the Three Phases of the Business Cycle," Journal of Business and Economic Statistics, 12, 269-277.

Storer, P. (1996), "Separating the Effects of Aggregate and Sectoral Shocks with Estimates from a Markov-Switching Search Model," Journal of Economic Dynamics and Control, 20, 93-121.

Town, R.J. (1992), "Merger Waves and the Structure of Merger and Acquisition Time-Series," Journal of Applied Econometrics, 7, S83-S100.

Turner, C.M., Startz, R., and Nelson, C.R. (1989), "A Markov Model of Heteroskedasticity, Risk, and Learning in the Stock Market," Journal of Financial Economics, 25, 3-22.

Vogelsang, T. (1999), “Two Simple Procedures for Testing for a Unit Root When There are Additive Outliers" Journal of Time Series Analysis, 20, 237-252.

Wynne, M.A., and Balke, N.S. (1996), “Are Deep Recessions Followed by Strong Recoveries? Results for the G-7 Countries," Applied Economics, 28, 889-897.

Wynne, M.A., and Balke, N.S. (1992), “Are deep recessions followed by strong recoveries?," Economics Letters, 39, 183-189.

Zivot, E., and Andrews, D.W.K. (1992), "Further Evidence on the Great Crash, the Oil Price Shock, and the Unit Root Hypothesis," Journal of Business and Economic Statistics, 10, 251-270. 
Markov-Switching in Trend Growth Rate Empirical Power of a 5\%-level Augmented Dickey Fuller Test

Table 1: $T=200$

$p_{00}$

\begin{tabular}{c|lll}
$p_{11}$ & $\mathbf{0 . 9}$ & $\mathbf{0 . 9 5}$ & $\mathbf{0 . 9 8}$ \\
\hline $\mathbf{0 . 5}$ & 0.125 & 0.308 & 0.329 \\
$\mathbf{0 . 6}$ & 0.239 & 0.310 & 0.157 \\
$\mathbf{0 . 7}$ & 0.154 & 0.080 & 0.246 \\
$\mathbf{0 . 8}$ & 0.059 & 0.054 & 0.120 \\
$\mathbf{0 . 9}$ & 0.061 & 0.039 & 0.203 \\
$\mathbf{0 . 9 5}$ & 0.056 & 0.045 & 0.098 \\
$\mathbf{0 . 9 8}$ & 0.140 & 0.114 & 0.080
\end{tabular}

Table 2: $T=500$

\begin{tabular}{l|lcl} 
& \multicolumn{3}{|c}{$p_{00}$} \\
$p_{11}$ & $\mathbf{0 . 9}$ & $\mathbf{0 . 9 5}$ & $\mathbf{0 . 9 8}$ \\
\hline $\mathbf{0 . 5}$ & 0.047 & 0.057 & 0.079 \\
$\mathbf{0 . 6}$ & 0.050 & 0.050 & 0.092 \\
$\mathbf{0 . 7}$ & 0.083 & 0.097 & 0.070 \\
$\mathbf{0 . 8}$ & 0.053 & 0.058 & 0.041 \\
$\mathbf{0 . 9}$ & 0.047 & 0.035 & 0.063 \\
$\mathbf{0 . 9 5}$ & 0.053 & 0.061 & 0.058 \\
$\mathbf{0 . 9 8}$ & 0.086 & 0.093 & 0.030
\end{tabular}

\section{Markov-Switching in Trend Growth Rate}

Empirical Power of a 5\%-level Perron $(1994,1997)$ Test

Table 3: $T=200$

$p_{00}$

\begin{tabular}{l|lll} 
& & & $p_{00}$ \\
$p_{11}$ & $\mathbf{0 . 9}$ & $\mathbf{0 . 9 5}$ & $\mathbf{0 . 9 8}$ \\
\hline $\mathbf{0 . 5}$ & 0.136 & 0.156 & 0.217 \\
$\mathbf{0 . 6}$ & 0.126 & 0.145 & 0.241 \\
$\mathbf{0 . 7}$ & 0.098 & 0.105 & 0.188 \\
$\mathbf{0 . 8}$ & 0.046 & 0.049 & 0.118 \\
$\mathbf{0 . 9}$ & 0.044 & 0.031 & 0.089 \\
$\mathbf{0 . 9 5}$ & 0.048 & 0.025 & 0.091 \\
$\mathbf{0 . 9 8}$ & 0.111 & 0.085 & 0.17
\end{tabular}

Table 4: $T=500$

\begin{tabular}{l|ccc} 
& \multicolumn{3}{|c}{$p_{00}$} \\
$p_{11}$ & $\mathbf{0 . 9}$ & $\mathbf{0 . 9 5}$ & $\mathbf{0 . 9 8}$ \\
\hline $\mathbf{0 . 5}$ & 0.045 & 0.055 & 0.065 \\
$\mathbf{0 . 6}$ & 0.030 & 0.050 & 0.060 \\
$\mathbf{0 . 7}$ & 0.035 & 0.095 & 0.075 \\
$\mathbf{0 . 8}$ & 0.030 & 0.050 & 0.050 \\
$\mathbf{0 . 9}$ & 0.045 & 0.055 & 0.025 \\
$\mathbf{0 . 9 5}$ & 0.035 & 0.035 & 0.050 \\
$\mathbf{0 . 9 8}$ & 0.055 & 0.060 & 0.020
\end{tabular}

\section{Markov-Switching in Trend Growth Rate} Empirical Power of a 5\%-level Zivot-Andrews (1992) Test

Table 5: $T=200$

\begin{tabular}{c|ccc} 
& \multicolumn{3}{|c}{$p_{00}$} \\
$p_{11}$ & $\mathbf{0 . 9}$ & $\mathbf{0 . 9 5}$ & $\mathbf{0 . 9 8}$ \\
\hline $\mathbf{0 . 5}$ & 0.236 & 0.194 & 0.732 \\
$\mathbf{0 . 6}$ & 0.135 & 0.427 & 0.427 \\
$\mathbf{0 . 7}$ & 0.399 & 0.248 & 0.348 \\
$\mathbf{0 . 8}$ & 0.096 & 0.359 & 0.353 \\
$\mathbf{0 . 9}$ & 0.162 & 0.086 & 0.202 \\
$\mathbf{0 . 9 5}$ & 0.115 & 0.086 & 0.183 \\
$\mathbf{0 . 9 8}$ & 0.244 & 0.277 & 0.331
\end{tabular}

Table 6: $T=500$

\begin{tabular}{c|ccc} 
& \multicolumn{3}{|c}{$p_{00}$} \\
$p_{11}$ & $\mathbf{0 . 9}$ & $\mathbf{0 . 9 5}$ & $\mathbf{0 . 9 8}$ \\
\hline $\mathbf{0 . 5}$ & 0.070 & 0.100 & 0.125 \\
$\mathbf{0 . 6}$ & 0.045 & 0.065 & 0.105 \\
$\mathbf{0 . 7}$ & 0.010 & 0.060 & 0.100 \\
$\mathbf{0 . 8}$ & 0.100 & 0.095 & 0.135 \\
$\mathbf{0 . 9}$ & 0.045 & 0.070 & 0.095 \\
$\mathbf{0 . 9 5}$ & 0.040 & 0.070 & 0.095 \\
$\mathbf{0 . 9 8}$ & 0.115 & 0.140 & 0.095
\end{tabular}




\section{Markov-Switching in the Transitory Component Empirical Power of a 5\%-level Augmented Dickey Fuller Test}

Table 7: $T=200$

\begin{tabular}{c|lcc} 
& \multicolumn{3}{|c}{$p_{00}$} \\
$p_{11}$ & $\mathbf{0 . 9}$ & $\mathbf{0 . 9 5}$ & $\mathbf{0 . 9 8}$ \\
\hline $\mathbf{0 . 5}$ & 1.000 & 0.996 & 1.000 \\
$\mathbf{0 . 6}$ & 0.998 & 0.999 & 0.994 \\
$\mathbf{0 . 7}$ & 0.998 & 0.991 & 0.993 \\
$\mathbf{0 . 8}$ & 0.992 & 0.976 & 0.965 \\
$\mathbf{0 . 9}$ & 0.954 & 0.865 & 0.790 \\
$\mathbf{0 . 9 5}$ & 0.875 & 0.697 & 0.534 \\
$\mathbf{0 . 9 8}$ & 0.812 & 0.523 & 0.297
\end{tabular}

Table 8: $T=500$

\begin{tabular}{c|ccc} 
& \multicolumn{3}{|c}{$p_{00}$} \\
$p_{11}$ & $\mathbf{0 . 9}$ & $\mathbf{0 . 9 5}$ & $\mathbf{0 . 9 8}$ \\
\hline $\mathbf{0 . 5}$ & 1.000 & 1.000 & 1.000 \\
$\mathbf{0 . 6}$ & 1.000 & 1.000 & 1.000 \\
$\mathbf{0 . 7}$ & 1.000 & 1.000 & 1.000 \\
$\mathbf{0 . 8}$ & 1.000 & 1.000 & 1.000 \\
$\mathbf{0 . 9}$ & 1.000 & 1.000 & 0.994 \\
$\mathbf{0 . 9 5}$ & 1.000 & 0.991 & 0.939 \\
$\mathbf{0 . 9 8}$ & 1.000 & 0.944 & 0.619
\end{tabular}


Markov-Switching in Autoregressive Parameters Empirical Power of a 5\%-level Augmented Dickey Fuller Test

$$
\mu_{1}=1.0, \rho_{1}=.8
$$

Table 9: $T=200$

$$
p_{00}
$$

\begin{tabular}{c|lcl}
$p_{11}$ & $\mathbf{0 . 9}$ & $\mathbf{0 . 9 5}$ & $\mathbf{0 . 9 8}$ \\
\hline $\mathbf{0 . 5}$ & 0.117 & 0.093 & 0.078 \\
$\mathbf{0 . 6}$ & 0.165 & 0.094 & 0.086 \\
$\mathbf{0 . 7}$ & 0.199 & 0.123 & 0.094 \\
$\mathbf{0 . 8}$ & 0.277 & 0.166 & 0.116 \\
$\mathbf{0 . 9}$ & 0.478 & 0.295 & 0.194 \\
$\mathbf{0 . 9 5}$ & 0.642 & 0.468 & 0.274 \\
$\mathbf{0 . 9 8}$ & 0.814 & 0.658 & 0.473
\end{tabular}

Table 11: $T=200$

\begin{tabular}{c|lcc} 
& \multicolumn{3}{c}{$p_{00}$} \\
$p_{11}$ & $\mathbf{0 . 9}$ & $\mathbf{0 . 9 5}$ & $\mathbf{0 . 9 8}$ \\
\hline $\mathbf{0 . 5}$ & 0.083 & 0.072 & 0.068 \\
$\mathbf{0 . 6}$ & 0.102 & 0.097 & 0.072 \\
$\mathbf{0 . 7}$ & 0.114 & 0.103 & 0.101 \\
$\mathbf{0 . 8}$ & 0.151 & 0.121 & 0.089 \\
$\mathbf{0 . 9}$ & 0.221 & 0.172 & 0.132 \\
$\mathbf{0 . 9 5}$ & 0.323 & 0.270 & 0.205 \\
$\mathbf{0 . 9 8}$ & 0.421 & 0.366 & 0.287
\end{tabular}

Table 10: $T=500$

\begin{tabular}{c|ccc} 
& \multicolumn{3}{|c}{$p_{00}$} \\
$p_{11}$ & $\mathbf{0 . 9}$ & $\mathbf{0 . 9 5}$ & $\mathbf{0 . 9 8}$ \\
\hline $\mathbf{0 . 5}$ & 0.433 & 0.136 & 0.076 \\
$\mathbf{0 . 6}$ & 0.495 & 0.189 & 0.089 \\
$\mathbf{0 . 7}$ & 0.627 & 0.259 & 0.095 \\
$\mathbf{0 . 8}$ & 0.742 & 0.348 & 0.134 \\
$\mathbf{0 . 9}$ & 0.932 & 0.641 & 0.230 \\
$\mathbf{0 . 9 5}$ & 0.993 & 0.830 & 0.408 \\
$\mathbf{0 . 9 8}$ & 0.999 & 0.963 & 0.732
\end{tabular}

$$
\mu_{1}=0.5, \rho_{1}=.9
$$

Table 12: $T=500$

\begin{tabular}{c|ccc} 
& \multicolumn{3}{|c}{$p_{00}$} \\
$p_{11}$ & $\mathbf{0 . 9}$ & $\mathbf{0 . 9 5}$ & $\mathbf{0 . 9 8}$ \\
\hline $\mathbf{0 . 5}$ & 0.148 & 0.090 & 0.053 \\
$\mathbf{0 . 6}$ & 0.190 & 0.086 & 0.074 \\
$\mathbf{0 . 7}$ & 0.272 & 0.125 & 0.090 \\
$\mathbf{0 . 8}$ & 0.392 & 0.173 & 0.095 \\
$\mathbf{0 . 9}$ & 0.640 & 0.347 & 0.158 \\
$\mathbf{0 . 9 5}$ & 0.857 & 0.610 & 0.321 \\
$\mathbf{0 . 9 8}$ & 0.946 & 0.847 & 0.591
\end{tabular}

$$
\mu_{1}=0.25, \rho_{1}=.95
$$

Table 13: $T=200$

\begin{tabular}{c|lcc} 
& \multicolumn{3}{|c}{$p_{00}$} \\
$p_{11}$ & $\mathbf{0 . 9}$ & $\mathbf{0 . 9 5}$ & $\mathbf{0 . 9 8}$ \\
\hline $\mathbf{0 . 5}$ & 0.068 & 0.063 & 0.075 \\
$\mathbf{0 . 6}$ & 0.086 & 0.082 & 0.089 \\
$\mathbf{0 . 7}$ & 0.088 & 0.082 & 0.094 \\
$\mathbf{0 . 8}$ & 0.090 & 0.109 & 0.112 \\
$\mathbf{0 . 9}$ & 0.108 & 0.132 & 0.102 \\
$\mathbf{0 . 9 5}$ & 0.172 & 0.142 & 0.153 \\
$\mathbf{0 . 9 8}$ & 0.168 & 0.171 & 0.166
\end{tabular}

Table 14: $T=500$

\begin{tabular}{c|ccc} 
& \multicolumn{3}{|c}{$p_{00}$} \\
$p_{11}$ & $\mathbf{0 . 9}$ & $\mathbf{0 . 9 5}$ & $\mathbf{0 . 9 8}$ \\
\hline $\mathbf{0 . 5}$ & 0.099 & 0.077 & 0.060 \\
$\mathbf{0 . 6}$ & 0.091 & 0.074 & 0.050 \\
$\mathbf{0 . 7}$ & 0.119 & 0.083 & 0.064 \\
$\mathbf{0 . 8}$ & 0.152 & 0.111 & 0.087 \\
$\mathbf{0 . 9}$ & 0.289 & 0.148 & 0.128 \\
$\mathbf{0 . 9 5}$ & 0.440 & 0.267 & 0.190 \\
$\mathbf{0 . 9 8}$ & 0.589 & 0.449 & 0.338
\end{tabular}


Markov-Switching in Trend Growth Rate

Empirical Size of a 5\%-level Augmented Dickey Fuller Test

Table 15: $T=200$

$$
p_{00}
$$

\begin{tabular}{c|ccc}
$p_{11}$ & $\mathbf{0 . 9}$ & $\mathbf{0 . 9 5}$ & $\mathbf{0 . 9 8}$ \\
\hline $\mathbf{0 . 5}$ & 0.051 & 0.067 & 0.049 \\
$\mathbf{0 . 6}$ & 0.066 & 0.068 & 0.068 \\
$\mathbf{0 . 7}$ & 0.052 & 0.067 & 0.055 \\
$\mathbf{0 . 8}$ & 0.057 & 0.059 & 0.067 \\
$\mathbf{0 . 9}$ & 0.055 & 0.033 & 0.062 \\
$\mathbf{0 . 9 5}$ & 0.056 & 0.047 & 0.055 \\
$\mathbf{0 . 9 8}$ & 0.146 & 0.099 & 0.063
\end{tabular}

Table 16: $T=500$

\begin{tabular}{c|lcl} 
& \multicolumn{3}{|c}{$p_{00}$} \\
$p_{11}$ & $\mathbf{0 . 9}$ & $\mathbf{0 . 9 5}$ & $\mathbf{0 . 9 8}$ \\
\hline $\mathbf{0 . 5}$ & 0.068 & 0.059 & 0.051 \\
$\mathbf{0 . 6}$ & 0.047 & 0.051 & 0.045 \\
$\mathbf{0 . 7}$ & 0.047 & 0.046 & 0.047 \\
$\mathbf{0 . 8}$ & 0.043 & 0.057 & 0.049 \\
$\mathbf{0 . 9}$ & 0.048 & 0.041 & 0.048 \\
$\mathbf{0 . 9 5}$ & 0.054 & 0.048 & 0.043 \\
$\mathbf{0 . 9 8}$ & 0.069 & 0.071 & 0.031
\end{tabular}

Markov-Switching in Trend Growth Rate Empirical Size of a 5\%-level Perron $(1994,1997)$ Test

Table 17: $T=200$

$p_{00}$

\begin{tabular}{c|ccc}
$p_{11}$ & $\mathbf{0 . 9}$ & $\mathbf{0 . 9 5}$ & $\mathbf{0 . 9 8}$ \\
\hline $\mathbf{0 . 5}$ & 0.068 & 0.045 & 0.056 \\
$\mathbf{0 . 6}$ & 0.063 & 0.042 & 0.061 \\
$\mathbf{0 . 7}$ & 0.052 & 0.046 & 0.063 \\
$\mathbf{0 . 8}$ & 0.048 & 0.061 & 0.052 \\
$\mathbf{0 . 9}$ & 0.049 & 0.043 & 0.061 \\
$\mathbf{0 . 9 5}$ & 0.047 & 0.030 & 0.052 \\
$\mathbf{0 . 9 8}$ & 0.087 & 0.053 & 0.044
\end{tabular}

Table 18: $T=500$

\begin{tabular}{c|ccc} 
& \multicolumn{3}{|c}{$p_{00}$} \\
$p_{11}$ & $\mathbf{0 . 9}$ & $\mathbf{0 . 9 5}$ & $\mathbf{0 . 9 8}$ \\
\hline $\mathbf{0 . 5}$ & 0.050 & 0.025 & 0.080 \\
$\mathbf{0 . 6}$ & 0.035 & 0.035 & 0.040 \\
$\mathbf{0 . 7}$ & 0.045 & 0.060 & 0.035 \\
$\mathbf{0 . 8}$ & 0.035 & 0.055 & 0.030 \\
$\mathbf{0 . 9}$ & 0.045 & 0.045 & 0.030 \\
$\mathbf{0 . 9 5}$ & 0.025 & 0.045 & 0.020 \\
$\mathbf{0 . 9 8}$ & 0.045 & 0.045 & 0.020
\end{tabular}

Markov-Switching in Trend Growth Rate Empirical Size of a 5\%-level Zivot-Andrews (1992) Test

Table 19: $T=200$

\begin{tabular}{l|ccl} 
& \multicolumn{3}{|c}{$p_{00}$} \\
$p_{11}$ & $\mathbf{0 . 9}$ & $\mathbf{0 . 9 5}$ & $\mathbf{0 . 9 8}$ \\
\hline $\mathbf{0 . 5}$ & 0.089 & 0.103 & 0.093 \\
$\mathbf{0 . 6}$ & 0.081 & 0.090 & 0.097 \\
$\mathbf{0 . 7}$ & 0.089 & 0.096 & 0.126 \\
$\mathbf{0 . 8}$ & 0.087 & 0.094 & 0.129 \\
$\mathbf{0 . 9}$ & 0.081 & 0.089 & 0.147 \\
$\mathbf{0 . 9 5}$ & 0.105 & 0.103 & 0.186 \\
$\mathbf{0 . 9 8}$ & 0.243 & 0.231 & 0.288
\end{tabular}

Table 20: $T=500$

\begin{tabular}{c|ccc} 
& \multicolumn{3}{|c}{$p_{00}$} \\
$p_{11}$ & $\mathbf{0 . 9}$ & $\mathbf{0 . 9 5}$ & $\mathbf{0 . 9 8}$ \\
\hline $\mathbf{0 . 5}$ & 0.070 & 0.035 & 0.050 \\
$\mathbf{0 . 6}$ & 0.070 & 0.060 & 0.070 \\
$\mathbf{0 . 7}$ & 0.055 & 0.085 & 0.070 \\
$\mathbf{0 . 8}$ & 0.045 & 0.075 & 0.090 \\
$\mathbf{0 . 9}$ & 0.105 & 0.080 & 0.090 \\
$\mathbf{0 . 9 5}$ & 0.050 & 0.070 & 0.080 \\
$\mathbf{0 . 9 8}$ & 0.100 & 0.095 & 0.075
\end{tabular}




\section{Markov-Switching in Variance}

Empirical Size of a 5\%-level Augmented Dickey Fuller Test

Table 21: $T=200$

$p_{00}$

\begin{tabular}{c|ccl}
$p_{11}$ & $\mathbf{0 . 9}$ & $\mathbf{0 . 9 5}$ & $\mathbf{0 . 9 8}$ \\
\hline $\mathbf{0 . 5}$ & 0.073 & 0.071 & 0.046 \\
$\mathbf{0 . 6}$ & 0.084 & 0.079 & 0.062 \\
$\mathbf{0 . 7}$ & 0.063 & 0.065 & 0.070 \\
$\mathbf{0 . 8}$ & 0.069 & 0.069 & 0.079 \\
$\mathbf{0 . 9}$ & 0.068 & 0.088 & 0.084 \\
$\mathbf{0 . 9 5}$ & 0.059 & 0.076 & 0.075 \\
$\mathbf{0 . 9 8}$ & 0.048 & 0.056 & 0.076
\end{tabular}

Table 22: $T=500$

\begin{tabular}{c|lcl} 
& \multicolumn{3}{|c}{$p_{00}$} \\
$p_{11}$ & $\mathbf{0 . 9}$ & $\mathbf{0 . 9 5}$ & $\mathbf{0 . 9 8}$ \\
\hline $\mathbf{0 . 5}$ & 0.058 & 0.048 & 0.053 \\
$\mathbf{0 . 6}$ & 0.066 & 0.063 & 0.041 \\
$\mathbf{0 . 7}$ & 0.045 & 0.048 & 0.059 \\
$\mathbf{0 . 8}$ & 0.062 & 0.060 & 0.072 \\
$\mathbf{0 . 9}$ & 0.054 & 0.064 & 0.047 \\
$\mathbf{0 . 9 5}$ & 0.058 & 0.038 & 0.070 \\
$\mathbf{0 . 9 8}$ & 0.049 & 0.057 & 0.058
\end{tabular}

Markov-Switching in Variance

Empirical Size of a 5\%-level Perron(1994, 1997) Test

Table 23: $T=200$

$p_{00}$

\begin{tabular}{c|ccc}
$p_{11}$ & $\mathbf{0 . 9}$ & $\mathbf{0 . 9 5}$ & $\mathbf{0 . 9 8}$ \\
\hline $\mathbf{0 . 5}$ & 0.116 & 0.133 & 0.123 \\
$\mathbf{0 . 6}$ & 0.139 & 0.132 & 0.139 \\
$\mathbf{0 . 7}$ & 0.117 & 0.166 & 0.126 \\
$\mathbf{0 . 8}$ & 0.125 & 0.169 & 0.185 \\
$\mathbf{0 . 9}$ & 0.124 & 0.171 & 0.214 \\
$\mathbf{0 . 9 5}$ & 0.100 & 0.162 & 0.198 \\
$\mathbf{0 . 9 8}$ & 0.089 & 0.115 & 0.161
\end{tabular}

Table 24: $T=500$

\begin{tabular}{c|ccc} 
& \multicolumn{3}{|c}{$p_{00}$} \\
$p_{11}$ & $\mathbf{0 . 9}$ & $\mathbf{0 . 9 5}$ & $\mathbf{0 . 9 8}$ \\
\hline $\mathbf{0 . 5}$ & 0.110 & 0.060 & 0.110 \\
$\mathbf{0 . 6}$ & 0.100 & 0.090 & 0.080 \\
$\mathbf{0 . 7}$ & 0.110 & 0.150 & 0.110 \\
$\mathbf{0 . 8}$ & 0.110 & 0.160 & 0.140 \\
$\mathbf{0 . 9}$ & 0.150 & 0.100 & 0.160 \\
$\mathbf{0 . 9 5}$ & 0.060 & 0.140 & 0.180 \\
$\mathbf{0 . 9 8}$ & 0.060 & 0.060 & 0.170
\end{tabular}

Markov-Switching in Variance

Empirical Size of a 5\%-level Zivot-Andrews (1992) Test

Table 25: $T=200$

$p_{00}$

\begin{tabular}{c|ccl}
$p_{11}$ & $\mathbf{0 . 9}$ & $\mathbf{0 . 9 5}$ & $\mathbf{0 . 9 8}$ \\
\hline $\mathbf{0 . 5}$ & 0.149 & 0.141 & 0.135 \\
$\mathbf{0 . 6}$ & 0.153 & 0.166 & 0.154 \\
$\mathbf{0 . 7}$ & 0.160 & 0.186 & 0.161 \\
$\mathbf{0 . 8}$ & 0.148 & 0.218 & 0.213 \\
$\mathbf{0 . 9}$ & 0.140 & 0.209 & 0.237 \\
$\mathbf{0 . 9 5}$ & 0.099 & 0.166 & 0.244 \\
$\mathbf{0 . 9 8}$ & 0.083 & 0.120 & 0.190
\end{tabular}

Table $26 T=500$

\begin{tabular}{c|ccc} 
& \multicolumn{3}{|c}{$p_{00}$} \\
$p_{11}$ & $\mathbf{0 . 9}$ & $\mathbf{0 . 9 5}$ & $\mathbf{0 . 9 8}$ \\
\hline $\mathbf{0 . 5}$ & 0.070 & 0.110 & 0.085 \\
$\mathbf{0 . 6}$ & 0.105 & 0.095 & 0.110 \\
$\mathbf{0 . 7}$ & 0.080 & 0.160 & 0.140 \\
$\mathbf{0 . 8}$ & 0.095 & 0.195 & 0.150 \\
$\mathbf{0 . 9}$ & 0.125 & 0.160 & 0.200 \\
$\mathbf{0 . 9 5}$ & 0.100 & 0.125 & 0.155 \\
$\mathbf{0 . 9 8}$ & 0.040 & 0.110 & 0.155
\end{tabular}




\section{Markov-Switching in the Transitory Component Empirical Size of a 5\%-level Augmented Dickey Fuller Test}

Table 27: $T=200$

\begin{tabular}{c|ccc} 
& \multicolumn{3}{c}{$p_{00}$} \\
$p_{11}$ & $\mathbf{0 . 9}$ & $\mathbf{0 . 9 5}$ & $\mathbf{0 . 9 8}$ \\
\hline $\mathbf{0 . 5}$ & 0.356 & 0.280 & 0.158 \\
$\mathbf{0 . 6}$ & 0.397 & 0.264 & 0.193 \\
$\mathbf{0 . 7}$ & 0.417 & 0.345 & 0.227 \\
$\mathbf{0 . 8}$ & 0.493 & 0.337 & 0.242 \\
$\mathbf{0 . 9}$ & 0.455 & 0.341 & 0.235 \\
$\mathbf{0 . 9 5}$ & 0.382 & 0.271 & 0.149 \\
$\mathbf{0 . 9 8}$ & 0.240 & 0.184 & 0.092
\end{tabular}

Table $28 T=500$

\begin{tabular}{l|rrr} 
& \multicolumn{3}{|c}{$p_{00}$} \\
$p_{11}$ & \multicolumn{1}{|c}{$\mathbf{0 . 9}$} & $\mathbf{0 . 9 5}$ & $\mathbf{0 . 9 8}$ \\
\hline $\mathbf{0 . 5}$ & 0.22 & 0.186 & 0.116 \\
$\mathbf{0 . 6}$ & 0.285 & 0.235 & 0.149 \\
$\mathbf{0 . 7}$ & 0.368 & 0.285 & 0.192 \\
$\mathbf{0 . 8}$ & 0.474 & 0.365 & 0.239 \\
$\mathbf{0 . 9}$ & 0.509 & 0.456 & 0.283 \\
$\mathbf{0 . 9 5}$ & 0.478 & 0.439 & 0.279 \\
$\mathbf{0 . 9 8}$ & 0.341 & 0.266 & 0.185
\end{tabular}

